\title{
Construindo um modelo didático 3D de baixo custo para facilitar a aprendizagem da membrana plasmática no Ensino Médio e Fundamental
}

\author{
Building a low-cost 3D didactic model to facilitate the learning of the plasma membrane in High \\ School and Elementary School \\ Construyendo un modelo didáctico 3D de bajo costo para facilitar el aprendizaje de la membrana \\ plasmática en la Escuela Secundaria e Primaria
}

\begin{abstract}
Resumo
Sendo caracterizada como um mosaico fluido, a membrana plasmática celular é uma bicamada composta de fosfolipídios e proteínas proposta por Singer e Nicolson em 1972. É uma estrutura tridimensional fascinante possuindo diversas funções como permitir a integridade e o transporte de substâncias para dentro e para fora da célula. Principalmente no Ensino Médio e no Fundamental, as disciplinas de Biologia e Ciências, possuem tópicos de Citologia, e os mesmos são encarados pelos alunos como complexos, abstratos, dificultando sua visualização e compreensão, uma vez que abordam estruturas tridimensionais microscópicas. Para vencer tais obstáculos e facilitar a aprendizagem dos alunos, este artigo propõe uma oficina com o objetivo de construção e abordagem de um modelo didático 3D da membrana plasmática das células eucarióticas, utilizando materiais simples e de baixo custo. Acreditase que, a confecção e a abordagem desse modelo 3D permitam facilitar o entendimento do tópico proposto, além de promover uma maior motivação dos alunos no processo de aprendizagem, despertando-se assim o lado lúdico e criativo dos discentes.
\end{abstract}

Palavras-chave: Membrana celular; Modelo didático 3D; Ensino; Biologia; Proteínas; Ciências.

\begin{abstract}
Being characterized as a fluid mosaic, the cell plasma membrane is a bilayer composed of phospholipids and proteins proposed by Singer and Nicolson in 1972. It is a fascinating three-dimensional structure with several functions such as allowing the integrity and transport of masses in and out of the cell. Especially in high school and elementary school, the subjects of Biology and Sciences, proper to Cytology, and they are seen by students as complex, abstract, making their visualization and understanding difficult, since they approach microscopic three-dimensional structures. To overcome such attempts and facilitate students' learning, this article proposes a workshop with the objective of building and approaching a 3D didactic model of the plasma membrane of eukaryotic cells, using simple and low-cost materials. It is believed that the making and approach of this 3D model facilitated the understanding of the proposed topic, in addition to promoting greater motivation of students in the learning process, thus awakening the playful and creative side of students.
\end{abstract}

Keywords: Cell membrane; 3D didactic model; Teaching; Biology; Proteins; Science.

\section{Resumen}

Al caracterizarse como un mosaico fluido, la membrana plasmática celular es una bicapa compuesta de fosfolípidos y proteínas propuesta por Singer y Nicolson en 1972. Es una fascinante estructura tridimensional con varias funciones como permitir la integridad y el transporte de masas hacia adentro y hacia afuera. de la celda. Especialmente em la Escuela Secundaria e Primaria, las disciplinas de Biología y Ciencia, propias de la Citología, y son vistas por los estudiantes como complejas, abstractas, dificultando su visualización y comprensión, ya que se trata de estructuras microscópicas tridimensionales. Para superar tales intentos y facilitar el aprendizaje de los estudiantes, este artículo propone un taller con el objetivo de construir y abordar un modelo didáctico 3D de la membrana plasmática de células eucariotas, utilizando materiales simples y de bajo costo. Se cree que la elaboración y planteamiento de este modelo 3D facilitó la comprensión del tema propuesto, además de promover una mayor motivación de los estudiantes en el proceso de aprendizaje, despertando así el lado lúdico y creativo de los estudiantes.

Palabras clave: Membrana celular; Modelo didáctico 3D; Enseñando; Biología; Proteínas; Ciencias. 


\section{Introdução}

A Citologia (termo que significa "estudo da célula"), também denominada de Biologia celular, é um assunto amplo da Biologia e está ligado a todos os outros ramos da ciência. Contudo, com o avanço científico é fácil perder-se nos detalhes e distrair-se com a sobrecarga de informações e terminologia técnica (Alberts et al. 2017).

A membrana plasmática é uma estrutura de grande importância para a vida celular, ela circunda a célula, define seus limites e permitem manter as diferenças cruciais entre o citosol e o ambiente extracelular (Alberts et al., 2010). Segundo Koolman e Röhm (2005), as membranas biológicas são constituídas por uma contínua camada dupla de lipídios anfipáticos que possuem $6 \mathrm{~nm}$ de tamanho na qual estão incrustradas diversas proteínas, possuindo adicionalmente carboidratos no seu lado externo. Nessa estrutura tridimensional, existem dois tipos de proteínas de membrana, as integrais e as periféricas. As integrais possuem domínios hidrofóbicos e penetram na bicamada fosfolipídica, muitas dessas formadas por estruturas bioquímicas denominadas alfa-hélices que atravessam a porção central da bicamada, já suas extremidades são hidrofílicas se estendendo ao ambiente aquoso em ambos os lados da membrana. (Sadava et al. 2009). Já as periféricas, segundo Reece et al. (2015), não estão embebidas na bicamada lipídica, porém se localizam nas suas extremidades. Sua estrutura molecular está evidenciada na Figura 1.

Figura 1. Esquema ilustrativo da membrana plasmática de uma célula animal (corte transversal).

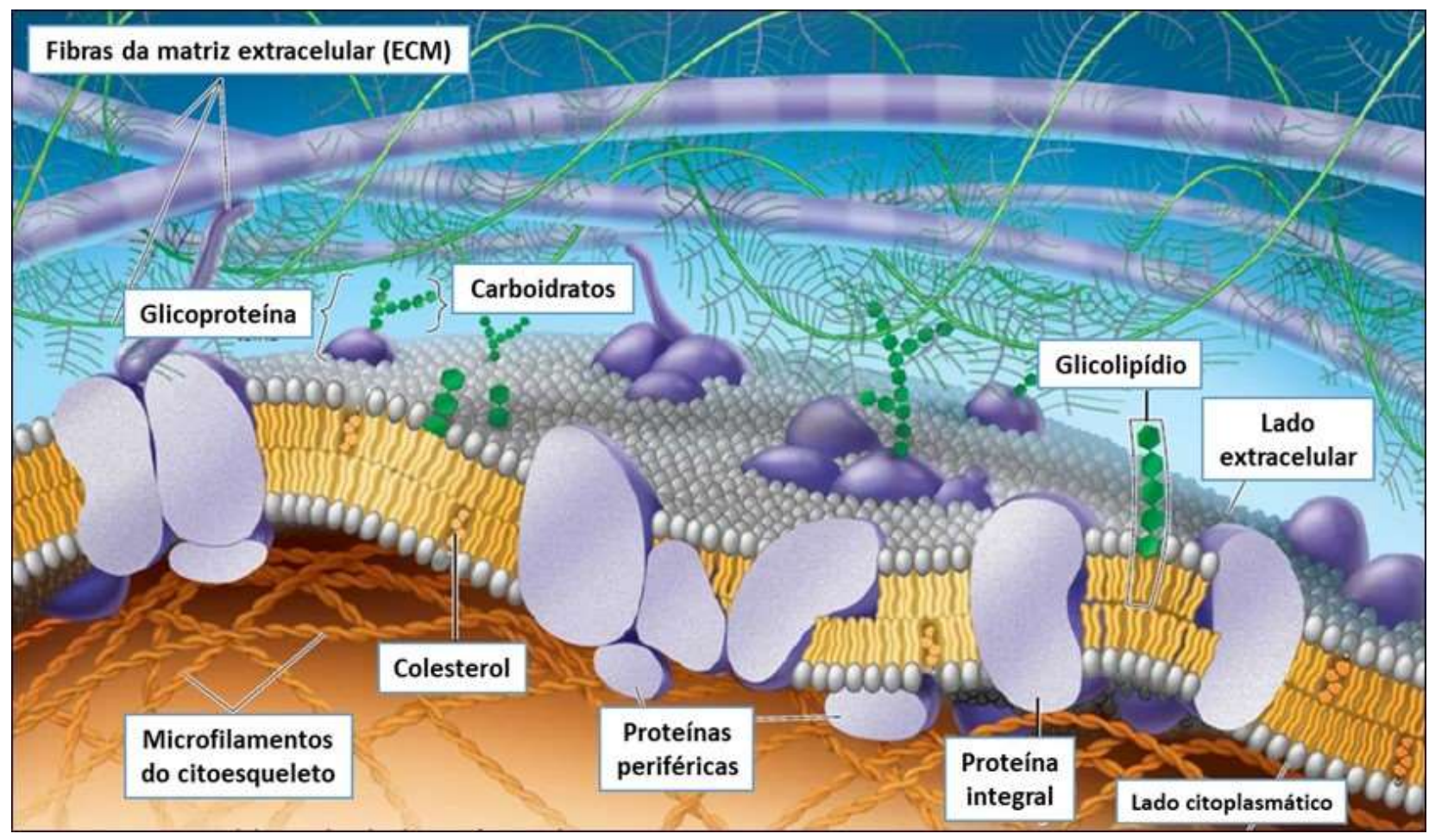

Fonte: Figura adaptada de Reece et al. (2015, p. 125), Figura 7.3. Licença para reprodução gentilmente cedida pela Editora Artmed.

Os carboidratos na membrana localizam-se na sua superfície externa, servindo como locais de reconhecimento de outras células e moléculas. Assim, essas estruturas podem estar inseridas a um lipídio (glicolipídio) ou ligados covalentemente a uma proteína (glicoproteína) (Sadava et al. 2009). De acordo com Reece et al. (2015), a membrana plasmática é o limite da vida, a fronteira que separa a célula viva do seu ambiente e controla o tráfego de dentro para fora e de fora para dentro da célula. Dessa forma, esses autores relatam que a membrana plasmática exibe um mosaico fluido (Singer \& Nicolson, 1972), sendo dotada por uma membrana fluida, com um "mosaico" de várias proteínas que se inserem em uma bicamada de fosfolipídios. Essas proteínas podem desempenhar várias funções como o transporte pela membrana, atividade enzimática, 
ligação de células a células vizinhas ou a matriz extracelular (Reece et al. 2017). A estrutura da bicamada fosfolipídica não é visível ao microscópio comum, mas sim por meio da microscopia eletrônica que é evidenciada por uma dupla linha contínua. (Curtis, 2011).

No ensino Fundamental, e principalmente no Ensino Médio, a área de Biologia Celular detém muitos termos e estruturas diminutas abstratas, dificultando sua visualização e compreensão pelos alunos. Assim, segundo Gonçalves (2021), a busca de metodologias alternativas de ensino, aliadas às aulas teóricas podem ser de grande relevância e impacto na sala de aula, possuindo como objetivo principal o de facilitar o processo de ensino e da aprendizagem. Sendo assim, pode-se destacar que uma dessas abordagens é a prática de modelos didáticos tridimensionais.

O modelo didático é definido como a representação de uma ideia objeto, evento, processo ou sistema, criado com um objetivo específico, dando ênfase em algo concreto (Gilbert, Boulter \& Elmer, 2000). De acordo com esses autores, a confecção de modelos representativos na ciência é de grande importância no processo de construção do conhecimento científico. O uso de modelo para representar na prática uma estrutura que é difícil de ser visualizada, já foi adotada por cientistas como Linus Pauling e Watson e Crick, o primeiro na área da química e o segundo na elucidação da estrutura da dupla hélice do DNA, na genética. Assim, o uso de modelos didáticos possui grande importância, pois facilita a aprendizagem, instiga os alunos ao trabalho em grupo na construção coletiva do conhecimento e a união entre a teoria e a prática (Gerpe, 2020).

Segundo Krasilchick (2004), os modelos didáticos são ferramentas utilizadas pelos professores com o intuito de mostrar objetos em três dimensões, podendo ser confeccionados pelos próprios alunos, utilizando-se materiais disponíveis no mercado como massa de modelagem, arames coloridos e até mesmo contas de plástico para representarem o desenvolvimento embrionário (Embriologia), síntese protéica (Genética) e divisão celular (Biologia Celular). Já, Carvalho e Oliveira (2021), ressaltam que, os modelos didáticos são dispositivos eficientes para o ensino e aprendizado de Citologia, possibilitando uma experiência lúdica aos alunos tornando-os proativos na construção do conhecimento. Nesse contexto, a prática da modelagem didática tridimensional, permite facilitar o ensino e a aprendizagem dos discentes, tornando o assunto mais cativante, propiciando ao professor efetuar uma discussão e problematização do que foi abordado, potencializando ainda mais a aprendizagem dos alunos. Assim, Souza et al. (2020) enfatizam que a utilização de modelos didáticos permite aumentar o interesse dos alunos ao longo das aulas promovendo-se assim uma interação mais participativa.

Orlando et al. (2009), construíram e utilizaram modelos didáticos tridimensionais por meio de materiais simples e de baixo custo, com o objetivo de facilitar o processo de ensino de tópicos de Biologia Celular e Molecular. Os autores relataram que o uso dessa ferramenta didática permitiu aos estudantes do Ensino Médio momentos de reflexão e criatividade, além de ter aumentado significativamente o interesse dos alunos pelos temas trabalhados.

Do mesmo modo, Zierer (2017) construiu e utilizou modelos didáticos utilizando materiais simples e de baixo custo no ensino de tópicos de Bioquímica. Como resultado, o autor verificou que o impacto do uso da modelagem foi muito promissor no processo de ensino e a aprendizagem, permitindo aos alunos a liberdade de expressão, desenvolvendo a busca do conhecimento pelos discentes nos tópicos abordados. Já, Silva et al. (2021, p. 1) utilizaram modelos didáticos de DNA, confeccionados por alunos da $3^{\text {a }}$ série do Ensino Médio, de uma escola pública do Piaú, para abordar conceitos básicos de genética. Como principal resultado desse trabalho, os autores relataram que

"os estudantes se sentiram motivados durante a confecção dos modelos didáticos de DNA, demonstrando a relevância de sua aplicação nas aulas de Biologia e no desenvolvendo do trabalho em equipe. Além disso, constatouse que somente a aula expositiva teórica não constitui uma metodologia eficaz para a aprendizagem dos assuntos de genética. Sendo importante, portanto, a utilização de metodologias ativas como: a construção e aplicação dos modelos didáticos, nos quais os alunos participam ativamente e tornam-se mediadores do próprio conhecimento" (Silva et al. 2021, p. 1). 
No Brasil, ainda é pouco comum escolas públicas com laboratórios de Biologia equipados com microscópios e materiais de pesquisa prontos para o uso dos alunos e do professor no nível de ensino fundamental e médio. Segundo o Instituto de Estudos e Pesquisas Educacionais Anísio Teixeira, Inep (2019), demonstram que apenas 38,8\% das escolas públicas dispõem de laboratórios de Ciências e Biologia para a elaboração de aulas práticas. Tal problemática pode ser atrelada a falta de recursos financeiros, inviabilizando a construção desses espaços físicos. Esses espaços são de grande importância no cotidiano da pesquisa e do ensino de biologia relacionados a temática de Citologia assim como ressaltam Cooper \& Hausman (2007). No entanto, pode-se alcançar resultados muito significativos no processo de ensino e de aprendizagem, utilizando a modelagem tridimensional com materiais alternativos e de baixo custo. Assim, o uso desse tipo de metodologia é de grande impacto no processo de ensino e aprendizagem, com o intuito de superar os obstáculos citados, onde o uso de laboratórios equipados com microscópios, para a observação das células ainda são restritos nas escolas.

Desta forma, o objetivo principal deste trabalho é a proposta de uma oficina para o desenvolvimento de modelagem tridimensional para facilitar a visualização e a aprendizagem do conteúdo de estrutura e função da membrana plasmática celular, na disciplina de Biologia e Ciências no Ensino Médio e Fundamental, respectivamente. Para essa proposta, os alunos irão utilizar materiais simples e de baixo custo para construir uma bicamada lipídica.

\section{Material e métodos}

\subsection{Materiais}

Os materiais utilizados na confecção do modelo didático tridimensional da membrana plasmática celular, foram:

- 70 bolas isopor de dimensão $35 \mathrm{~mm}(3,5 \mathrm{~cm}$ de diâmetro cada);

- 1 unidade de cola de isopor de $35 \mathrm{~g}$;

- 2 caixas de palitos de dente;

- Cola de isopor (uma unidade de $37 \mathrm{ml}$ );

- Fio elétrico emborrachado colorido;

- Massa de biscuit na cor verde (1 unidade de $90 \mathrm{~g}$ );

-Tinta acrílica ou PVA de $37 \mathrm{ml}$ nas cores: rosa (2 unidades), vermelho (1), azul claro (1), azul real (1), verde (1) e amarelo (1);

- 1 papel cartão amarelo (pode ser utilizado cartolina);

- Durex;

- Grampeador;

- Tesoura sem ponta;

- 1 pincel;

- Etiquetas para identificação dos componentes da membrana.

\subsection{Procedimentos para confecção da bicamada de fosfolipídios e suas proteínas}

A bicamada de fosfolipídios foi construída utilizando bolas de isopor (que é representado pelo grupo colina + fosfato + glicerol) e por palitos de dente, que representam as caudas dos ácidos graxos. As bolas de isopor foram pintadas na cor rosa, unindo-as umas às outras por meio de palitos de dente fincados e colados por meio do uso da cola de isopor até formar uma camada (primeira camada da membrana). Após secagem, os palitos de dente foram fincados (dois a dois) que representaram as caudas dos fosfolipídios. Recomenda-se pintar cada um dos palitos de dente para evidenciar maior essas estruturas, dando a ideia de profundidade. A segunda camada foi feita da mesma maneira que a primeira. Os palitos de dente das quatro 
extremidades das camadas de fosfolipídos foram colados uns aos outros com fita durex, para possibilitar maior rigidez a estrutura.

As proteínas foram compostas por meio de bolas de isopor pintadas com cores, como por exemplo o azul, o verde etc. Os carboidratos que compõem as glicoproteínas foram confeccionados com massa de biscuit verde (em formato de pequenas bolinhas). Essas bolinhas foram enroladas e colocadas no palito de dente, que foi fincado na superfície da bola de isopor na membrana. A proteína canal de cálcio foi confeccionada por meio de um papel cartão amarelo formando um cilindro com aproximadamente $20 \mathrm{~cm}$ de altura e foi unido com grampeador e durex. Um corte na sua extremidade frontal pode ser recomendado, com a função de permitir a visualização dos íons cálcio (representados por bolas de isopor amarelas) sendo transportados entre a membrana. Já a proteína alfa-hélice foi construída por meio de um fio elétrico emborrachado retorcido, sendo fincado nas extremidades da bicamada (bolas de isopor). O tamanho total do modelo poderá ficar em torno de $25 \mathrm{~cm}$ de comprimento por 10 a $12 \mathrm{~cm}$ de altura. Assim, o tamanho é ideal para o seu manuseio, transporte e alocação na sala de aula.

Por fim, devido à atual situação em que vivemos da COVID-19, a confecção do modelo didático 3D proposto pode ser feito em casa pelos próprios alunos, que, ao final irão responder um questionário sendo posteriormente enviado ao professor para correções e discussões futuras. Vale a pensa ressaltarmos que essa atividade possui tempo médio de duração de 1 hora e 20 minutos. No Quadro 1, estão dispostos de maneira sucinta o objetivo, o conteúdo e as habilidades que o professor pode abordar aos alunos com a realização da presente atividade.

Quadro 1. Objetivo, conteúdo e habilidades trabalhados na atividade proposta.

\begin{tabular}{|c|c|}
\hline Competências & Descrição \\
\hline Objetivo da atividade prática & $\begin{array}{l}\text { Facilitar a compreensão e visualização da estrutura } \\
\text { tridimensional da membrana celular aos discentes do } 1^{\circ} \text { ano } \\
\text { do Ensino Médio e do } 9^{\circ} \text { ano do Ensino Fundamental. }\end{array}$ \\
\hline Conteúdo abordado & Citologia (Biologia Celular, Biomembranas). \\
\hline Habilidades & $\begin{array}{l}\text { Desenvolver no aluno a prática de abstração e criatividade na } \\
\text { construção e interpretação de modelos didáticos } \\
\text { tridimensionais. }\end{array}$ \\
\hline
\end{tabular}

Fonte: Autores (2021).

Abaixo, estão algumas questões e suas respostas esperadas que podem ser utilizadas pelo professor no final da atividade prática, com o intuito de potencializar e avaliar a aprendizagem dos discentes.

\subsection{Questões propostas}

1) Explique o porquê que a membrana plasmática dos glóbulos vermelhos necessita de proteínas em sua estrutura.

2) Qual a função das membranas biológicas em uma célula? Imagine se essa estrutura não existisse. O que poderia acontecer com as células desses seres vivos?

3) Porquê dizemos que a membrana plasmática é um mosaico fluído? Explique.

4) Ao observar o modelo 3D confeccionado por você, faça um desenho esquemático, registrando as principais estruturas, descrevendo suas respectivas funções. 


\subsection{Respostas esperadas das questões}

1) As proteínas presentes na membrana celular dos glóbulos vermelhos desempenham a função de auxiliar no transporte de substâncias, além disso promove a célula uma sustentação e estruturação maior, pois os glóbulos vermelhos ficam constantemente em atrito na corrente sanguínea em detrimento ao movimento da corrente circulatória.

2) A membrana plasmática desempenha as funções de transporte de substâncias, delimitação entre o meio extracelular e o meio intracelular, além de desempenhar funções de reconhecimento entre as células. Se não existissem as membranas, as células não teriam sua identidade e território sendo inexistente o transporte de substâncias (moléculas, gases, etc.), sendo assim incompatível com a vida.

3) A membrana plasmática é um mosaico fluido pois os fosfolipídios e as proteínas estão inseridas como um mosaico, estando em constante movimento (fluido).

4) Resposta pessoal do aluno.

\section{Resultados e Discussão}

Na Figura 2, encontra-se disposto o modelo didático tridimensional da membrana plasmática eucariótica, construída com o uso de materiais simples e de baixo custo. Nele, pode-se notar o plano frontal da bicamada de fosfolipídios. Nessa estrutura temos todas as proteínas, glicoproteínas além dos fosfolipídios e carboidratos, compondo um mosaico fluido. Comentar com os alunos que os fosfolipídios da membrana, possuem uma parte com grande afinidade a água (cabeça polar) e uma parte hidrofóbica a água (cauda apolar). Dessa maneira, a cabeça fica voltada para dentro e para fora da membrana, e as caudas ficam voltadas para a face interna da membrana. Chamar a atenção dos alunos na proteína canal. Questioná-los sobre qual seria o papel dessa proteína nas membranas celulares dos organismos. A proteína canal, é de extrema importância para a célula, pois moléculas iônicas podem atravessar a membrana por meio delas. No modelo didático está sendo simulado o transporte de íons cálcio, do meio extracelular para o meio intracelular por meio de uma proteína canal. Discutir com os alunos a importância do cálcio dentro da célula. Esse íon pode estar ligado no controle de geração de ATP (energia). Relembrar os alunos que as bombas de sódio e potássio também são proteínas canais, no entanto diferentemente das proteínas canais de cálcio, elas gastam energia, e funcionam por meio de um gradiente de concentração. 
Figura 2. Modelo didático 3D da membrana plasmática celular eucariótica. Em amarelo, a proteína canal. Escala em cm.

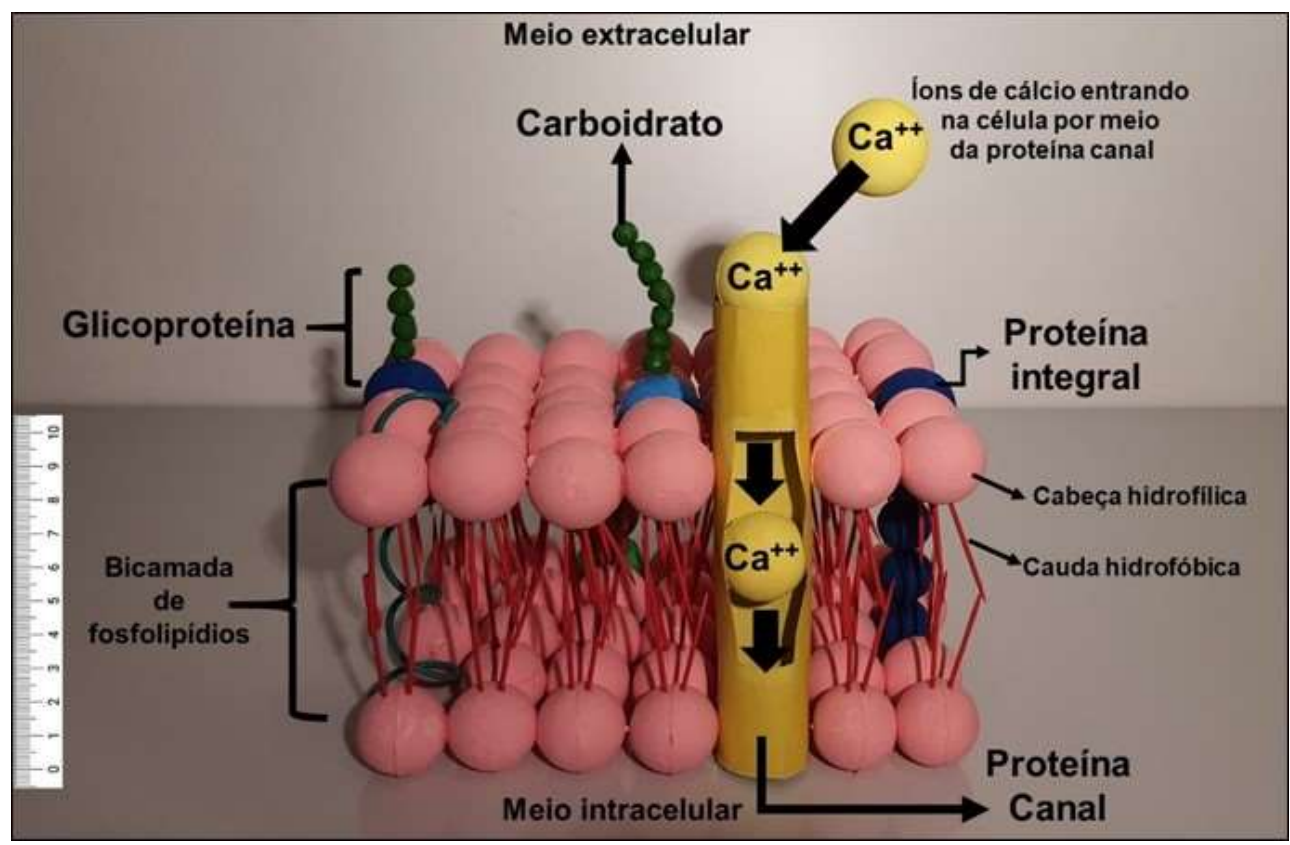

Fonte: Autores (2021).

Na Figura 3, temos em evidência a estrutura proteica da alfa-hélice, que foi representada por meio de um fio elétrico retorcido emborrachado verde. Esse domínio proteico atravessa a bicamada lipídica, partindo do meio extracelular e chegando no domínio intracelular. Salientar aos alunos que este tipo de domínio proteico, desempenha diversas funções dentro da célula, e uma delas é facilitar o transporte de substâncias, além daqueles realizados pelas proteínas canais.

Figura 3. Estrutura 3D do modelo da membrana plasmática. Notar na lateral o domínio proteico da alfa-hélice, confeccionado por meio de um fio elétrico emborrachado verde. Escala em $\mathrm{cm}$.

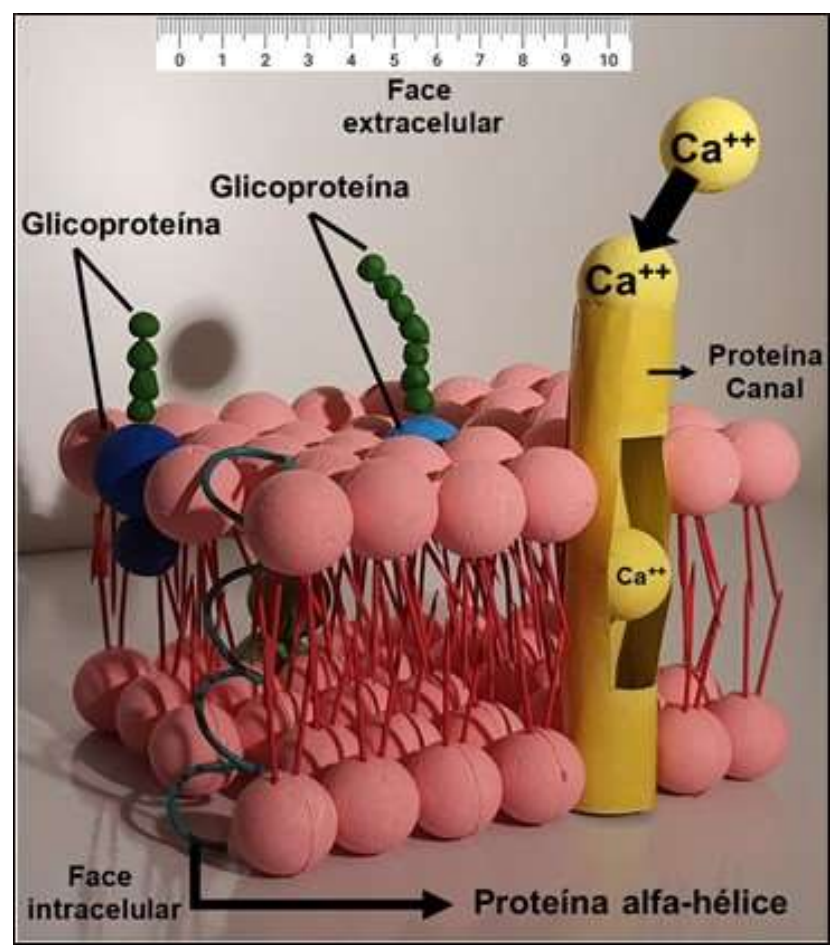

Fonte: Autores (2021). 
Na Figura 4 estão em evidência outros tipos de proteínas que podem ocorrer na estrutura tridimensional da membrana plasmática. Na Figura 4a está disposta uma proteína parcial de membrana, ou seja, uma proteína periférica (bolas maiores verdes). Já na Figura 4b, temos em bolas azuis mais escuras, uma proteína de domínio integral de membrana. Nessa etapa da discussão, comentar com os alunos que essa grande diversidade de formas de proteínas encontradas na membrana plasmática, garante a ela um maior controle no transporte de substâncias, uma vez que essas proteínas podem desempenhar diversos papéis diferentes.

Figura 4. Estrutura 3D da membrana plasmática. a) presença na face direita lateral do domínio proteico da alfa-hélice, no esquerdo a proteína periférica de membrana (verde) b) em azul mais escuro, o destaque para a proteína integral de membrana. Escala em cm.

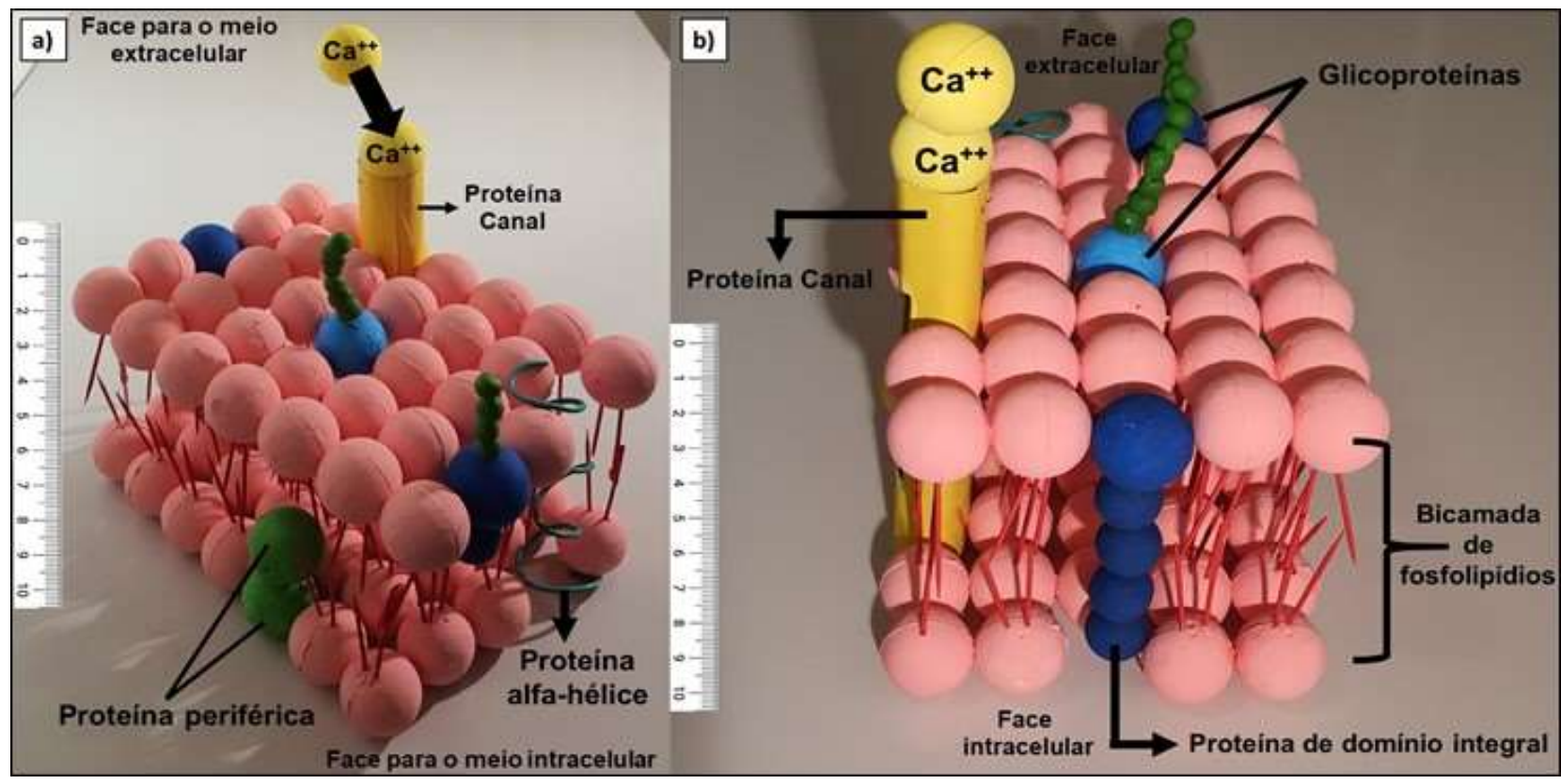

Fonte: Autores (2021).

O modelo didático confeccionado, também permite ao professor revisar com os alunos sobre os mecanismos de transporte que podem ocorrer por meio da bicamada celular, como a difusão, difusão facilitada, transporte ativo, osmose, endocitose e exocitose. Resgatar com os alunos os conceitos de meio isotônico, hipertônico e hipotônico que podem ocorrer nas células animais como consequência do processo de osmose (Silva Júnior \& Sasson, 2005). Considerar sobre essa questão o que ocorre nas células vegetais, com os fenômenos que tornam as células túrgidas, flácidas e plasmolisadas e quando a célula perde água por evaporação, sendo definida como uma célula murcha ao ar (Silva Júnior \& Sasson, 2005). Outra problematização importante é ressaltar a função dos lipídios presentes na estrutura da biomembrana, destacando sua estrutura química (Figura 5), além de correlacionar suas principais funções dentro dos seres vivos como isolante térmico e o auxílio na condução de estímulos elétricos (na bainha de mielina nos neurônios). Lembrar aos alunos sobre a estrutura química dos fosfolipídios da membrana. Estes, são longas estruturas formadas por moléculas de ácidos graxos (cauda apolar - hidrofóbica) em conjunto com uma unidade de colina, de fosfato e de glicerol (formando a cabeça polar - hidrofílica) - (Figura 5). Vale a pena destacarmos que para os alunos do nível Fundamental, o professor poderá modificar o modelo didático da membrana plasmática aqui proposto, permitindo sua adaptação e simplificação. 
Figura 5. Fosfolipídios presentes na membrana, sua estrutura química. Escala em $\mathrm{cm}$.

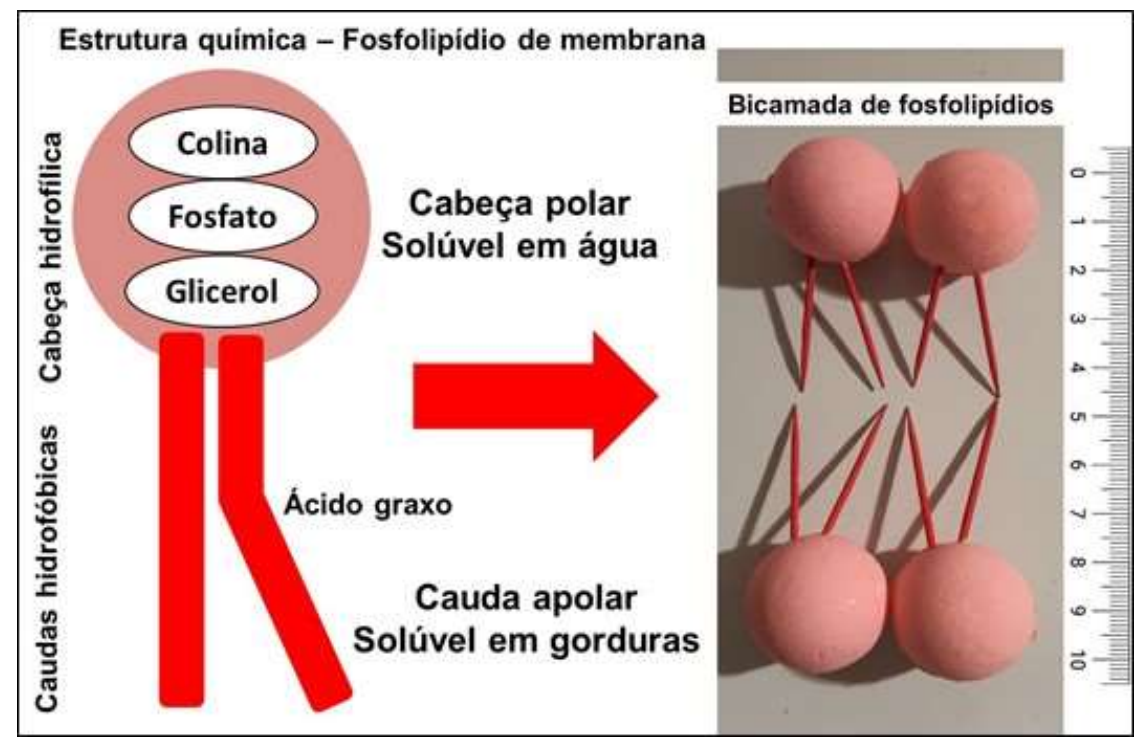

Fonte: Autores (2021).

O uso da modelagem didática tridimensional utilizando materiais simples e de baixo custo possui grande importância no ensino e aprendizagem dos alunos, pois segundo Silva et al. (2021), a prática da modelagem didática permite aumentar o interesse e a motivação pelo aprendizado. Sendo, portanto, um recurso didático com grande utilidade e com valor pedagógico, uma vez que estes materiais são confeccionados com materiais simplificados, com custo baixo, sendo facilmente adquiridos pelos próprios alunos.

Podemos destacar ainda que, os modelos didáticos tridimensionais constituem uma metodologia de ensino com grande valor didático, no que tange a facilitação do ensino e da aprendizagem dos alunos com deficiências visuais. Deste modo, Michelotti e Loreto (2019) ressaltam que, a compreensão de estruturas celulares, pela natureza microscópica, exige um alto grau de abstração, o que se torna um desafio aos alunos com e sem limitação visual. Metodologias alternativas podem proporcionar aos alunos visualizarem, manipularem, tocarem em modelos que representem as verdadeiras estruturas celulares, auxiliando assim o aprendizado.

\section{Conclusões}

O uso da modelagem 3D utilizando materiais simples e de baixo custo pode ser de grande impacto no ensino da estrutura e da função da membrana plasmática aos alunos. Assim, por se tratar de um tópico abstrato e microscópico, a confecção e o uso da modelagem tridimensional da membrana celular, permitem que os alunos possam ampliar sua criatividade, potencializando assim o processo de aprendizagem do tópico proposto, além de aumentar a interação entre os discentes.

Como perspectivas futuras deste trabalho, o professor poderá propor aos alunos construírem outros modelos didáticos tridimensionais como por exemplo, as células animais, vegetais, bacterianas e até mesmo a estrutura morfológica tridimensional do núcleo celular eucariótico, evidenciando seus constituintes e funções.

Assim, esse trabalho se desponta como muito promissor tornando as aulas mais criativas e interessantes, no entanto, tal recurso metodológico deve ser mais incentivado e praticado pelos professores aos alunos, dentro das disciplinas de Biologia e Ciências no Ensino Médio e Fundamental, respectivamente. 


\section{Agradecimentos}

Gostaria de agradecer a editora Artmed por permitir a publicação modificada da figura 7.3 pertencente a obra de Reece et al. (2105, p. 125).

\section{Referências}

Alberts, B., Johnson, A., Lewis, J., Raff, M., Roberts, K., \& Walter, P. (2010). Biologia Molecular da Célula. (5a ed,) Artmed, 1268p.

Alberts, B., Bray, D., Hopkin, K., Johnson. A., Lewis, J., Raff, M., Roberts, K., \& Walter, P. A. (2017). Fundamentos da Biologia Celular. (4a ed.) Artmed, $838 \mathrm{p}$.

Carvalho, C. L. L., \& Oliveira, D. B. (2021). O uso de modelos didáticos no ensino e aprendizagem de citologia. Brazilian Journal of Development. 7(2), 14765-14768. https://www.brazilianjournals.com/index.php/BRJD/article/view/24558

Cooper, G. M., \& Hausman, R. E. (2007). A Célula: uma abordagem molecular. (3a ed.) Artmed, 717p.

Curtis, H. (2011). Biologia. (2a ed.), Guanabara Koogan, 964p.

Gerpe, R, L. (2020). Modelos didáticos para o ensino de Biologia e Saúde: produzindo e dando acesso ao saber científico. Educação Pública, 20(15), 1-5. https://educacaopublica.cecierj.edu.br/artigos/20/15/modelos-didaticos-para-o-ensino-de-biologia-e-saude-produzindo-e-dando-acesso-ao-saber-cientifico

Gilbert, J. K., Boulter, C. J., \& Elmer, R. (2000). Positioning Models in Science Education and in Design and Technology Education, en Gilbert, J. K. and Boulter, C. J. (eds.). Developing Models in Science Education, pp. 3-17. Dordrecht: Kluwer.

Gonçalves, T. M. (2021). A guerra imunológica das células contra os patógenos: a proposta de um modelo didático tridimensional de baixo custo para simulação da resposta imune celular mediada por linfócitos $\mathrm{T}$ CD8 ${ }^{+}$. Brazilian Journal of Development, 7(1), 4.854-4.860. https://www.brazilianjournals.com/index.php/BRJD/article/view/23099/18554

Inep, (2019). Instituto Nacional de Estudos e Pesquisas Educacionais Anísio Teixeira, Dados do censo escolar. http://portal.inep.gov.br/artigo//asset_publisher/B4AQV9zFY7Bv/content/dados-do-censo-escolar-noventa-e-cinco-por-cento-das-escolas-de-ensino-medio-tem-acesso-a-internet-masapenas-44-tem-laboratorio-de-ciencias/21206

Silva Júnior, C., \& Sasson, S. (2005). Biologia: volume 1: As características da vida Biologia Celular Vírus: entre moléculas e células A origem da vida Histologia Animal. (8a ed.), Saraiva, 400p.

Koolman, J., \& Röhm, K. H. (2005). Bioquímica - Texto e Atlas. (3a ed.) Artmed, 478p.

Krasilchik, M. (2004). Prática de Ensino de Biologia. Edusp, 199p.

Michelotti, A., \& Loreto, E. L. S. (2019). Utilização de modelos didáticos tateáveis como metodologia para o ensino de biologia celular em turmas inclusivas com deficientes visuais. Revista Contexto \& Educação. 34(109), 150-169. http://dx.doi.org/10.21527/2179-1309.2019.109.150-169

Milo, R., \& Philips, R. (2016) Cell by the numbers. Garland Science, Taylor \& Francis Group, 356p.

Orlando, T. C., Lima, A. R., Silva, A. M., Fusisaki, C., Ramos, C. L., Machado, D., Fernandes, F. F., Lorenzi, J. C. C., Lima, M. A., Gardim, S., Barbosa, V. C., \& Trez, T. A. (2009). Planejamento, montagem e aplicação de modelos didáticos para abordagem de Biologia Celular e Molecular no Ensino Médio por graduandos de Ciências Biológicas. Revista Brasileira de Ensino de Bioquímica e Biologia Molecular, 10, 1-17. http://bioquimica.org.br/revista/ojs/index.php/REB/article/view/33

Reece, J. B., Urry, L. A., Cain, M. L., Wasserman, S. A., Minorsky, P. V., \& Jackson, R. B. (2015). Biologia de Campbell. (10a ed,) Artmed, 1442p.

Sadava, D., Heller, H. C., Orians, G. H., Purves, W. K., \& Hillis, D. M. (2009). Vida A Ciência da Biologia. Volume I: Célula e Hereditariedade. (8a ed.) Artmed, 461p.

Silva, J. S., Oliveira, N. C. R., Sousa, F. S., Neto, C. Q. S., Saraiva, E. S., Brito, M. V., Sá, G. H., \& Amorim, L. V. (2021). Research, Society and Development. 10(2). 1-9. http://dx.doi.org/10.33448/rsd-v10i2.120051

Singer, S. J., \& Nicolson, G. L. (1972). The Fluid Mosaic Model of the Structure of Cell Membranes. Science, 175(4023), 720-731. http://web.as.uky.edu/Biology/faculty/cooper/bio350/Bio350\%20Labs/WK1-Circuit\%20board\%20Lab/lipids.pdf

Souza, K. M. S., Souza, A. T. V., Cavalcanti, M. T. H., Porto, A. L. F., \& Bezerra, A. L. P. (2020). Elaboração de modelos moleculares reutilizando materiais para o ensino da bioquímica. Cadernos de Educação Básica. 5(2), 1-17. http://www.cp2.g12.br/ojs/index.php/cadernos/article/view/2772

Zierer, M. S. (2017). A construção e a aplicação de modelos didáticos no ensino de Bioquímica. Revista Brasileira de Ensino de Bioquímica e Biologia Molecular, 15, 202-211, 2017. http://bioquimica.org.br/revista/ojs/index.php/REB/article/view/691 